5. Brown AFT, Hamilton DL. Tick bite anaphylaxis in Australia. J Accid Emerg Med 1998; 15(2): 111-3.

6. Gauci M, Loh RKS, Stone BF, Thong YH. Allergic reactions to the Australian paralysis tick, Ixodes holocyclus: diagnostic evaluation by skin test and radioimmunoassay. Clin Exp Allergy 1989; 19: 279-83.

7. Kemp A. Tick bites. Med J Aust 1986; 144: 615.

8. Grattan-Smith PJ, Morris JG, Johnston HM, Yiannikas C, Malik R, Russell R, et al. Clinical and neurophysiological features of tick paralysis. Brain 1997; 120: 102-13.

9. Barber PA, Chambers ST, Parkin PJ. Australian paralysis tick bite. N Z Med J 1994; 107(980): 252-3.

10. Pearn J. The clinical features of tick bite. Med J Aust 1977; 2: 313-8.

11. Storer E, Sheridan A, Warren L, Wayte J. Ticks in Australia. Australas J Dermatol 2003; 44(2): 83-9.

12. Stewart A, Glass J, Patel A, Watt G, Cripps A, Clancy R. Lyme arthritis in the Hunter Valley. Med J Aust 1982; 1(3): 139.
13. Hudson BJ, Barry RD, Shafren DR, Wills MC, Caves S, Lennox VA. Does Lyme borreliosis exist in Australia? $J$ Spirochetal Tick-Borne Dis 1994; 1(2): 46-51.

14. Russell RC, Doggett SL, Munro R, Ellis J, Avery D, Hunt C, et al. Lyme disease: a search for a causative agent in ticks in southeastern Australia. Epidemiol Infect 1994; 112(2): 375-84.

15. Piesman J, Stone BF. Vector competence of the Australian paralysis tick, Ixodes holocyclus, for the Lyme disease spirochete Borrelia burgdorferi. Int J Parasitol 1991; 21(1): 109-11.

16. Needham GR. Evaluation of five popular methods for tick removal. Pediatrics 1985; 75(6): 997-1002.

17. Stone BF, Binnington KC, Gauci M, Aylward JH. Tick-host interactions for Ixodes holocyclus: role, effects, biosynthesis and nature of its toxic and allergenic oral secretions. Exp Appl Acarol 1989; 7: 59-69.

\title{
A SURVEY OF BEDBUGS IN SHORT-STAY LODGES
}

\section{Nathan Ryan \\ Environmental Health Unit \\ City of Sydney Council}

\section{Bryce Peters and Peter Miller \\ Department of Health Sciences \\ University of Technology, Sydney}

An increase in the number of anecdotal reports of bedbug infestations in short-stay lodge-type accommodation used by backpackers and other budget travellers in the City of Sydney prompted a pilot survey to determine the extent of the problem. The aim of the survey was obtain the perspective of the lodge managers on bedbug problems and how they handled them. This article describes the survey results and assesses the effectiveness of the methods of control reported.

\section{BACKGROUND}

Bedbugs have long been associated with humans and have been a significant problem for accommodation providers for centuries. The bug uses its piercing proboscis to feed on human blood at night and lays eggs in bedding and furniture. Bedbug bites can cause significant irritation, and some individuals are particularly sensitive. While posing a potential problem, bedbugs are not known to be vectors of disease. ${ }^{1,2}$ Only the common bedbug Cimex lectularius has been found in Sydney to date, although the tropical bedbug Cimex hemipterus may be a recent import, given the number of travellers arriving from northern Australia and Asia, where it is endemic, and given that this species was recently recognised in Queensland. ${ }^{3}$
Infestations of bedbugs have traditionally been associated with poor sanitation, but the dramatic resurgence of bedbug activity in Australia and overseas may be attributed to a number of different causes. ${ }^{4}$ The introduction of residual insecticides and improved standards of domestic hygiene have significantly reduced the bedbug problem but a number of recent studies indicate a reappearance of bedbugs overseas and in Australia. $^{5-8}$ Increasing complaints of bedbugs by shortstay guests, including reports to the City of Sydney's Environmental Health Unit, the South Eastern Sydney Public Health Unit, and local doctors, prompted us to conduct a survey of the situation in short-stay lodges in Sydney.

Short-stay guests are an important component of Australian tourism, contributing around 20 per cent of the total number of tourists. Following recent council amalgamations, the enlarged City of Sydney now has about 6,000 short-stay beds in around 65 lodges, some of which have been in continuous operation for more than 15 years. Guests stay an average of 3-4 days. Many of these guests have spent time in lodges throughout Europe, Asia and Australia, where they may have been exposed to bedbugs before arriving in Sydney, although there is no evidence of transmission of bedbugs from other countries to Australia or from other states to New South Wales.

\section{SURVEY REVEALS EXTENT OF THE PROBLEM}

All 52 short-stay lodges on the City of Sydney City register before the council amalgamation were asked to participate 
in a pilot survey to provide a complete picture of the bedbug problem in the industry. Between October and December 2003, face-to-face interviews were conducted at 47 of the 52 short-stay lodges chosen for the survey ( 5 lodges declined to participate). Face-to-face surveys were conducted in preference to mail-return surveys to ensure a high response rate and to allow the authors to view the premises at close hand. Infestations reported by guests were initially confirmed by the managerial or cleaning staff of the lodges. A complaint from 1 guest, and our visual inspections of 4 of the premises with active infestations during the survey, confirmed the presence of bedbugs. The species of bedbug was not identified.

We asked the lodge operators about their history of infestations over the past year and whether the problem recurred after their preferred treatment, which included both chemical and non-chemical approaches. A high proportion of premises (79 per cent, or 37/47 lodges) reported some bedbug activity in the preceding 12 months. Of these, more than one-half reported 3 or more outbreaks; that is, reports of guests being bitten or confirmed infestations. Most lodge operators reported that the problem was increasing, with long-term operators regarding the last 2 years as their worst ever for bedbugs. A follow-up report from 1 participant operator indicated that up to 35 per cent of their beds were infected. This raises the issue that the closure of any beds, or whole rooms, for treatment of bedbugs has a significant economic effect, both in terms of the cost of professional treatment and lost bed rentals.

The number of reported infestations peaked in the summer months, coinciding with increased numbers of tourists returning from northern Australia. The infestations were not related to the age, construction material, bedding material or apparent level of hygiene of the lodges. Twothirds of the short-stay lodges had some kind of regular pest control program in place, often supplied by pest control operators and usually intended for control of cockroaches, but these were not generally effective against bedbugs. One-third of lodges had no regular pest control program.

\section{REPORTED CONTROL METHODS WERE INEFFECTIVE}

After an initial bedbug pesticide treatment, either by the lodge operator or by a pest control operator, 57 per cent of responding lodges suffered a repeat infestation in the room treated, mostly within 1 month. That is, the lodge operators either found live bedbugs and/or received reports of guests being bitten by bedbugs. This showed that the current treatment methods and/or insecticides were ineffective. Less than half of the lodge owners followed up initial treatment with a second application of insecticide. Insecticidal agents applied by the lodge operators included various flea bombs, sprays, cockroach baits and ant dusts, and bleach or borax powder. Many lodge operators claimed that currently available pesticides were ineffective, but this was probably more due to poor choice of agent or application than any chemical resistance. For example, cockroach baits and borax are not designed to kill bedbugs.

Non-chemical means of controlling bedbug infestations had equally poor results. Most lodge operators routinely banned the use of sleeping bags in dormitories. When an infestation was reported, many hostel operators insisted that backpackers washed their clothes and linen in hot water, but few operators confirmed the usefulness of these measures. Also, the backpacks may not have been included in the cleaning and washing process and may have acted as a source of reinfestation.

A number of unorthodox measures were employed to control infestations or rid an infected room of bedbugs. One lodge operator reported sprinkling bleach powder around the bed and crumpled camphor into skirting boards. A number of operators reported dipping the ends of wooden slats from bunk beds into boiling water or bleach. Similarly, hot water was poured between floor cracks and skirting boards to kill eggs. Some operators just sprayed mattresses with domestic insecticides. One operator believed that smoking tobacco in a room would prevent bedbugs from biting the occupants. A number of operators used tea-tree (melaleuca) or eucalyptus oils in the belief that these would repel the bedbugs.

It was evident from the responses that many of the lodge operators lacked sufficient knowledge about effective bedbug treatments. Information that is freely available on the internet or from pest control operators was not commonly accessed. One worrying belief among lodge operators was that professional pest control treatments did not work any better than those domestic treatments described above, suggesting that lodge operators needed advice about the value of professional treatment.

\section{RECOMMENDATIONS FORTHOROUGH TREATMENT}

For successful control of bedbugs, one must kill adult, nymph and egg forms of the pest, preferably using a residual insecticide and follow-up treatments. Mechanical means of removing bugs (burning, squashing and scrubbing) are highly labour-intensive and are effective only in the areas they reach: too many places in a room that harbour bugs may be overlooked for these methods to be reliable on their own. Good housekeeping, such as regular vacuuming around skirting boards, is often recommended as a preventative strategy. Steam can also be very effective in controlling bedbugs; one study from the United States showed that steam cleaning of mattresses gave more effective long-term control than did chemicals. ${ }^{9}$

Chemical control is more effective (if applied correctly) as it eliminates current infestations and protects against subsequent infestations, although this depends on the 
insecticides used. ${ }^{10}$ Bedbugs have shown resistance to most major insecticide groups but the most appropriate insecticide is still permethrin. ${ }^{11,12}$ A residual formulation is recommended to control emerging nymphs and also those nymphs and adults not directly treated. In an ideal environment, adult bedbugs may live for up to 6 or even 12 months without blood feeding, waiting in stored furniture and bedding for their next opportunity to feed. A thorough insecticide treatment regime is vital, including reapplication of insecticides after 1-2 weeks to allow for new eggs to hatch.

Lodge guests must accept that they contribute to the problem by spreading bedbugs in their luggage. Not all insect bites are due to bedbugs, so when an infestation is suspected this should be confirmed by looking for bedbugs as they bite, in the mattress or in luggage and clothing. While many people show no immediate signs or pain from bites, delayed reactions up to 9 days later have been reported. ${ }^{13}$ About one-quarter of people are very sensitive and may show severe reactions that are best treated with antihistamines and topical steroids. ${ }^{14}$

\section{SOME POSITIVE OUTCOMES}

A major benefit of this survey is that the operators of short-stay lodges are now openly discussing the bedbug issue and effective ways to deal with it. This more open attitude will assist further training of lodge operators. Upcoming initiatives of the City of Sydney Council include the production of information packs for lodge operators and guests, and the promotion of better control methods as up-to-date information becomes available to local government, industry associations and pest control operators. Training environmental health inspectors to identify these problems may also assist lodge operators with how to manage a bedbug infestation in their premises and may assist complainants with how to manage a bedbug infestation on their person.

\section{CONCLUSION}

The extent of bedbug infestations is a consequence of various factors such as: the insects' 'hitching a ride' on travellers and their luggage; changes in pest management; appropriate training in the pest management industry; and a reluctance of the accommodation industry to report the problem. ${ }^{4}$ The City of Sydney has the largest short-stay lodge industry of any local government area in New South Wales, which is often both the first and the last port of call for short-stay guests. Their high mobility may facilitate the transfer of bedbugs around Australia and overseas.

Most short-stay lodge operators asked for clear information regarding simple treatment programs, and for more information for travellers on how to minimise their risk. A more open approach to the problem of bedbugs in Sydney, including awareness of the issue and education about effective control steps, will go some way to reducing the number of infestations.

\section{ACKNOWLEDGEMENTS}

The authors would like to thank the following for assistance with this project: Jim Mann and Ali Khalife, University of Technology, Sydney, for assisting with interviewing; Dr Harry Wilson, University of Technology, Sydney, for preliminary editing of the manuscript; Toni Cains, South Eastern Sydney Public Health Unit, for reports on bedbug infestations; Merilyn Geary, Department of Medical Entomology, Institute of Medical Pathology and Clinical Research, Westmead, for information on the identity of bedbug species in Sydney; Stephen Doggett, Department of Medical Entomology, Institute of Medical Pathology and Clinical Research, Westmead, for his generous comments and suggestions on the final version of the article; and the lodges that participated in the project.

\section{REFERENCES}

1. Goddard J. Do bed bugs carry human diseases? A controversy. Pest Control Technol 2003; 31: 38-40.

2. Blow JA, Turell MJ, Silverman AL, Walker ED. Stercorarial shedding and transtadial transmission of hepatitis B virus by common bed bugs (Hemiptera: Cimicidae). J Med Entomol 2001; 38: 694-700.

3. Doggett SL, Geary MJ, Crowe WJ, Wilson P, Russell RC. Has the tropical bed bug Cimex hemipterus (Hemiptera: Cimicidae), invaded Australia? Environ Health 2003; 3(4): 80-83.

4. Doggett SL, Geary MJ, Lamond P, Russell RC. Between the sheets with bed bugs: their ecology and control. Prof Pest Manage 2004; April-May: 25-27.

5. Krueger L. Don't get bitten by the resurgence of bedbugs. Pest Control 2000; 68: 58-64.

6. Koehler P, Harlan H. Bedbugs: infestations on the rise. Health Med Weekly 2001; August 27: 6-7.

7. Paul J, Bates J. Is infestation with the common bed bug increasing? BMJ 2000; 320: 1141.

8. Institute of Medical Pathology and Clinical Research: Bed bugs: Fact sheet. Sydney: Institute of Medical Pathology and Clinical Research, Westmead Hospital, October 2003.

9. Meeks F. Bed bugs bite back. PCTOnline 2003; July 44-52. Available online at www.pctonline.com.

10. Fletcher MG, Axtell RC. Susceptibility of the bedbug, Cimex lectularius, to selected insecticide and various treated surfaces. Med Vet Entomol 1993; 7: 69-72.

11. Myamba J, Maxwell CA, Asidi A, Curtis CF. Pyrethroid resistance in tropical bedbugs, Cimex hemipterus, associated with the use of treated bednets. Med Vet Entomol 2002; 16: 448-51.

12. Feroz M. Biochemistry of malathion resistance in a strain of Cimex lectularius resistant to organophosphorus compounds. Bull World Health Organ 1971; 45: 795-804.

13. Sansom JE, Reynolds NJ, Peachey RDG. Delayed reaction to bed bug bites. Arch Dermatol 1992; 128: 272-3.

14. Cleary CJ, Buchanan D. Diagnosis and management of bedbugs. Nurse Prac 2004, 29: 47-8. 